\title{
NĖŠČIUUJŲ RINITAS
}

\author{
Mantilè Juotkutė, Dovilė Karaliūtė \\ Lietuvos sveikatos mokslu universitetas
}

Raktažodžiai: nėččiųjų rinitas, sloga, nėštumas, obstrukcija, užgulta nosis.

\section{Santrauka}

Tyrimo tikslas - išsiaiškinti rinito priežastis, simptomus néštumo metu ir taikomus diagnostikos bei gydymo metodus, aprašytus literatūroje.

Tyrimo metodas. Sisteminè literatūros apžvalga. Straipsniai atrinkti iš elektroninès duomenų bazès PubMed (Medline), naudojant raktažodžius ,,rhinitis during pregnancy“ ir ,pregnancy induced rhinitis“.

Rezultatai. Néščiųjų rinitas yra dažna patologija, stebima kone pusei visų nėščiųjų. Tai būklè, esanti tik néštumo metu ir pasireiškianti neuždegiminiu, nealerginiu nosies gleivinès pokyčiu, kuri sukelia vieną ar daugiau simptomų: nosies obstrukciją, rinorèją, nosies niežulį, čiaudulį, hiposmiją. Rinitui atsirasti įtakos turi hormoninis organizmo persitvarkymas néštumo metu. Literatūros duomenimis, po gimdymo ši būklè praeina per dvi savaites, tačiau laiku nediagnozuota ir tinkamai negydoma gali sukelti komplikacijas, riziką vaisiui ir pabloginti néštumo baigti.

Išvados. Nėščiujų rinitas dažnai sukelia simptomus, kurie veikia motinos, o kartu ir vaisiaus gyvenimo kokybę. Ypač svarbus šios patologijos etiologijos supratimas, laiku priimti diagnostikos bei gydymo sprendimai, otorinolaringologų ir akušerių-ginekologų bendradarbiavimas, mokant pacientes valdyti ligą.

\section{Ivadas}

Jau XVIII amžiuje buvo pastebėta, jog nosies užburkimas, sloga bei kiti susiję simptomai gali būti susiję su nèštumu [1]. Něščiujų rinitas (lot. Rinopathia gravidarum) - dažna néščiujų būklè, apibūdinama kaip ilgą laiką trunkanti nosies obstrukcija dèl gleivinių paburkimo ir padidejusios sekrecijos, išsivystanti bet kuriame (dažniausiai - antrame ar trečiame) nèštumo trečdalyje ir išnykstanti per 2 savaites po gimdymo [2]. Tai išskirtinai něštumui būdinga būklè, prasidedanti nesant infekcijos, alergijos ar požymių, leidžiančių įtarti piktybinio proceso sukeltą rinito išsivystymą
[3]. Nëščiųjų rinitas priskiriamas prie hormonų pokyčių sukeliamų rinitų, jis išskiriamas ir kaip nealerginis rinitas kartu su menstruacinio ciklo, brendimo ir menopauzès sukelto hormonų disbalanso rinitais [2]. Naujų šios patologijos tyrimų nedaug, nors moterų, patiriančiu gyvenimo kokybę bloginančius rinito simptomus skaičiai yra ganètinai dideli.

Tyrimo tikslas - išsiaiškinti ir aptarti dažniausiai literatūroje aprašomas nëščiujų rinito priežastis, simptomus ir taikomus diagnostikos bei gydymo metodus.

\section{Tyrimo medžiaga ir metodai}

Tyrimo metodas - sisteminė literatūros apžvalga. Atrinkti straipsniai, kuriuose aprašomas nėščujų rinitas, jo sukeliami simptomai bei diagnostikos ir gydymo galimybès. Apžvalga atlikta naudojantis elektronine duomenų baze PubMed (Medline).

\section{Tyrimo rezultatai}

Etiologija ir rizikos veiksniai. Něščiujų rinitas - dažna patologija. Numatoma, jog apie 18-30 proc. moterų patirs rinito simptomus něštumo metu, tačiau tikètinas patologijos pasireiškimo dažnis svyruoja nuo 9 iki 53 procentų $[1,4,5]$. Tyrimais nustatyta, jog dèl nëščiosios nosies gleivinèje esančių lytinių hormonų receptorių prasideda gleivinès pokyčiai, tačiau neaišku, kaip tiksliai lytiniai hormonai veikia šiuos receptorius [2]. Svarbi ir visa su něštumu susijusių organizmo pokyčių ir veiksnių, tokių kaip padidejęs kraujo kiekis moters organizme, sumažejęs vazomotorinis tonusas, edemos, susijusios su plazmos tekejjimu ị nosies stromą, kombinacija [1]. Ypač svarbu stebėti moteris, kurioms rinitas jau buvo pasireiškęs nėštumo metu, néščiąsias, turinčias polinkị sirgti alerginiu, infekciniu arba kitų žalingų aplinkos veiksnių sukeltu rinitu ir tas, kurioms nustatytas lètinis sinusitas arba obstrukcinè miego apnèja, kadangi tai yra vieni svarbiausių něšciujų rinito rizikos veiksnių [5].

Simptomai ir rizika. Pirmiausiai ir dažniausiai pasireiškiantis nëščujų rinito simptomas - nosies obstrukcija $[1,2,4]$. Ji gali pasireikšti kartu su sloga, čiauduliu, nosies ir gerklès perštėjimu, uoslès sutrikimu, pasunkejjusiu kvèpavimu arba ir nesant šių simptomų. Svarbu paminèti, jog 
něščiujų rinitas gali progresuoti ir sudaryti nosies polipus [1]. Rinito sukeliama obstrukciné miego apneja siejama su vaisiaus hipoksija bei augimo sulètejjimu, prastesne naujagimio būkle pagal Apgar, nëščiosios hipertenzinių būklių išsivystymo rizika [5].

Diagnostika. Něščiujų rinitą nustatyti galima atsižvelgiant ị ligos istoriją, nusiskundimus, apžiūrą, bet specialių tyrimų ar laboratorinių priemonių diagnozei patvirtinti nèra [4,6-8]. Něščiujų rinitas dažniausiai yra subjektyvi diagnozė $[6,8]$, o tyrimų duomenimis dauguma moterų $(96 \%)$ patiria daugiau nei vieną simptomą [2], todèl reikalinga labai išsami anamnezè [9]. Itarti galima esant nosies užgulimui, kurio nebuvo anksčiau, nėra sukeltas kitų būklių ir simptomai vargina 2 dienas iš eilès daugiau nei 1 valandą $[4,10]$.

Nosies obstrukciją galima įvertinti subjektyviomis (VAS, NOSE) bei objektyviomis (rinoskopija, nazoendoskopija, rinomanometrija, akustinè rinometrija, maksimalus nosies ikvepiamo oro srauto matavimas) priemonemis, o tyrimo išvadas galima kiekybiškai ịvertinti tik subjektyviomis skalemis, tokiomis kaip DIP, VAS ir NOSE. Tai i pacientą orientuoti klausimynai, kuriais galima ịvertinti nosies užgulimo laipsni, gyvenimo kokybę. DIP yra priemonè gydytojui, nosies endoskopiniams radiniams įvertinti $[6,8]$. Jei NOSE

1 lentelè. NOSE skalè $[6,8]$.

\begin{tabular}{|l|c|c|c|c|c|}
\hline \multirow{2}{*}{ Simptomai } & \multicolumn{5}{|c|}{ Problemos dydis } \\
\cline { 2 - 6 } & $\begin{array}{c}\text { nè- } \\
\text { ra }\end{array}$ & $\begin{array}{c}\text { ma- } \\
\text { ža }\end{array}$ & $\begin{array}{c}\text { vidu- } \\
\text { tinè }\end{array}$ & $\begin{array}{c}\text { di- } \\
\text { delè }\end{array}$ & $\begin{array}{c}\text { rim- } \\
\text { ta }\end{array}$ \\
\hline Nosies užgulimas (pilnumas) & 0 & 1 & 2 & 3 & 4 \\
\hline $\begin{array}{l}\text { Nosies obstrukcija (užsikimši- } \\
\text { mas) }\end{array}$ & 0 & 1 & 2 & 3 & 4 \\
\hline Sunku kvépuoti per nosi & 0 & 1 & 2 & 3 & 4 \\
\hline Miego sutrikimai & 0 & 1 & 2 & 3 & 4 \\
\hline $\begin{array}{l}\text { Neužtenka oro kvėpuojat per nosì } \\
\text { fizinio krūvio metu }\end{array}$ & 0 & 1 & 2 & 3 & 4 \\
\hline
\end{tabular}

2 lentelè. DIP skalè $[6,8]$.

\begin{tabular}{|l|c|c|c|}
\hline Požymiai & Nèra & Vidutinis & Sunkus \\
\hline Sekretas & 0 & 5 & 10 \\
\hline Uždegimas & 0 & 5 & 10 \\
\hline Polipai (edema) & 0 & 5 & 10 \\
\hline
\end{tabular}

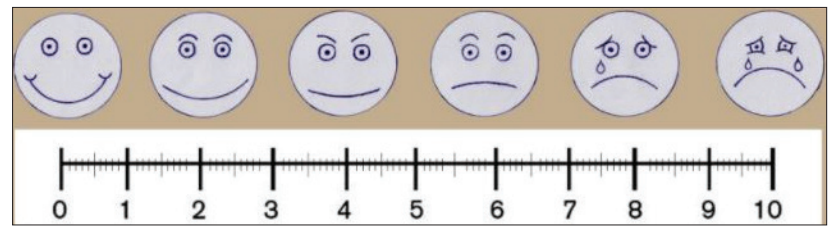

1 pav. VAS $[6,8]$
(1 lentelè), DIP (2 lentelè) ir VAS (1 pav.) balai yra didesni nei 5, laikoma, jog tai yra něšciųų rinitas [8].

Dẻl panašių simptomų ị kitas nosies ligas, něščiujų rinitas turètų būti įtariamas nesant kitų priežasčių, o esminis skirtumas yra nusiskundimų atsiradimo laikas $[2,8,11,12]$. Reikètų atmesti alergini, infekcinį, vaistų sukeltą, vazomotorinį rinitą, nosies pertvaros iškrypimus, polipus, rinosinusitą $[4,6,8]$. Vienas dažniausių yra alerginis rinitas, kuriam būdingas sekreto tekėjimas iš nosies ir čiaudulys, o tai nèra dominuojantys simptomai néščiujų rinito metu $[2,4,13]$. Rinitas gali komplikuotis rinosinusitu dèl nosị ir sinusus siejančių kraujagyslinių, nervinių ir anatominių kelių [14] ir yra astmos bei kitų rinitų rizikos veiksnys $[2,9,15]$. İtariant rinosinusitą, radiologinio ištyrimo reikètų vengti, ypač pirmajame trimestre, nes radiacija gali paveikti vaisiaus nervų sistemą [11].

Rinitas něštumo metu turi įtakos gyvenimo kokybei, nes sukelia nemalonius pojūčius dèl sudirgusios nosies gleivinès, gali sukelti rimtas motinos ir vaisiaus komplikacijas $[5,12,13]$. Kuo anksčiau nustatoma diagnozè, tuo greičiau galima pradėti tinkamą gydymą, kuris svarbus tiek néščiosios, tiek vaisiaus gerovei $[5,6]$.

Gydymas. Rinito gydymas nèštumo metu sutelktas i minimalią intervenciją, reikalingą simptomams palengvinti, o ne ligai išgydyti, nes ši būkle praeina savaime po gimdymo $[4,5,8,11]$. Otorinolaringologas bei akušeris-ginekologas turi atsižvelgti ị gydymo priemonių, vaistų saugumą, dabartinị jų ịrodymų lygị ir pasverti gydymo naudą bei galimą žalą $[4,8,16]$. Gydytojai turi paaiškinti pacientems, kad nosies užgulimas néštumo metu yra dažnas reiškinys ir suteikti informaciją apie gydymo galimybes [8]. Néščiosios paprastai neįtraukiamos ị klinikinius tyrimus, todèl trūksta informacijos apie daugumą vartojamų vaistų, o nèštumo metu rinitui gydyti nèra specialių medikamentų $[7,12,17]$.

Gydymo galimybès apima farmakologines ir nefarmakologines priemones. Nefarmakologinis gydymas: fizinis aktyvumas, galvos pakèlimas $30^{\circ}-45^{\circ}$ miegant, nosies sparnelius plečiantys prietaisai (išoriniai ir vidiniai), nosies plovimas druskos tirpalu. Daugeliui moteru šios priemonès padeda, jos yra gerai toleruojamos, nesukellia šalutinių reiškinių, nereikalingas ar sumažinamas medikamentinio gydymo poreikis [4-9,11,12,18,19]. Rinitui galima taikyti ir farmakologines priemones: dekongestantus, steroidus $[5,6,8,12,13,18,19]$. Medikamentinį gydymą reikia skirti atsargiai, mažiausiomis dozèmis ir tik esant indikacijų, nes gali sukelti nepageidaujamą poveikį. Pavyzdžiui, piktnaudžiavimas vietiniais nosies dekongestantais gali sukelti vaistų indukuotą rinitą, todèl juos galima naudoti tik 3-5 dienas [4,5,7,8,11]. Medikamentu nerekomenduojama skirti pirmame trimestre, nes tai rizikingiausias laikotarpis apsigimimams atsirasti $[4,8,11,12]$. 
Nosies lašai yra naudingi esant sunkioms obstrukcijoms, bet juos reikia tinkamai lašinti (aukštai užvertus galvą), kad būtų pasiektas ostiomeatalinis kompleksas [9]. Nors nosies purškalai neabsorbuojami į kraujotaką, tačiau jų saugumas nèštumo metu nèra įrodytas, o perteklinis vaistų ar intervencijų vengimas gali sumažinti riziką vaisiui $[11,13,16]$. Yra daugybè alternatyvių gydymo būdų (akupunktūra, kompresai, eteriniai aliejai, garų inhaliacijos ir kt.), tačiau nedaug irodymų, patvirtinančių galimą naudą, o galimas šalutinis poveikis ar rizika dažnai ignoruojami [20]. Chirurginio gydymo néštumo metu reikètų vengti, nebent taikomos priemonès neveiksmingos ir nèra kitos išeities [4,7-9]. Néštumo rinitas yra dažna problema, todèl reikia ieškoti naujų, alternatyvių, individualių terapinių strategijų mažinti simptomus, vengiant rizikos vaisiui $[15,18]$.

\section{Išvados}

1. Nëščiujų rinitas - dažna klinikinè būklè, sukelianti něšciosios diskomfortą ir pasireiškianti įvairiais simptomais, dažniausiai - nosies obstrukcija.

2. Rinitas néštumo metu remiasi subjektyvia diagnoze, todèl būtina tiksli anamnezè, kuri padètų diferencijuoti nuo kitos kilmès rinito.

3. Ankstyva diagnostika ir gydymas yra svarbūs něščiosios gyvenimo kokybei, tačiau tyrimo metodai bei intervencijos turi būti gerai apgalvoti ir kuo saugesni motinai ir vaisiui.

\section{Literatūra}

1. Orban N, Maughan E, Bleach N. Pregnancy-induced rhinitis. Rhinology 2013;51:111-9.

https://doi .org/10.4193/Rhin12.045

2. Baudoin T, Šimunjak T, Bacan N, Jelavić B, Kuna K, Košec A. Redefining pregnancy-induced rhinitis. Am J Rhinol Allergy 2020.

https://doi .org/10.1177/1945892420957490

3. Friebe-Hoffmann U, Lindemann J. Update Schwangerschaftsrhinitis. Z Geburtshilfe Neonatol 2017;221:59-66.

https://doi .org/10.1055/s-0042-110325

4. Caparroz FA, Gregorio LL, Bongiovanni G, Izu SC, Kosugi EM. Rhinitis and pregnancy: literature review. Braz J Otorhinolaryngol. Associação Brasileira de Otorrinolaringologia e Cirurgia Cérvico-Facial 2016;82:105-11.

https://doi .org/10.1016/j.bjorl.2015.04.011

5. Profile SEE. Pregnancy induced rhinitis : a systemic review of biomedical and pharmaceutical sciences. 2021.

6. Ulkumen B, Artunc Ulkumen B, Pala HG, Celik O, Sahin N, Karaca G, et al. Pregnancy rhinitis in Turkish women: do gestational week, BMI and parity affect nasal congestion? Pakistan J Med Sci 2016;32:950-4.

https://doi .org/10.12669/pjms.324.10164
7. Goanţa CM, Cîrpaciu D, Tuşaliu M, Budu VA. Pregnancy rhinitis. Arch Balk Med Union 2018;53:114-6.

https://doi .org/10.31688/ABMU.2018.53.3.24

8. Poerbonegoro NL. Nasal congestion and its management in pregnancy rhinitis. Indones J Obstet Gynecol 2019;7:318-26. https://doi .org/10.32771/inajog.v7i4.977

9. Scadding GK, Kariyawasam HH, Scadding G, Mirakian R, Buckley RJ, Dixon T, et al. BSACI guideline for the diagnosis and management of allergic and non-allergic rhinitis. Clin Exp Allergy 2017;47:856-89.

https://doi .org/10.1111/cea.12953

10. Mullol J, del Cuvillo A, Lockey RF. Rhinitis phenotypes. J Allergy Clin Immunol Pract Elsevier Inc 2020;8:1492-503. https://doi .org/10.1016/j.jaip.2020.02.004

11. Kar M, Bayar Muluk N, Negm H. How should rhinitis be managed during pregnancy? Challenges Rhinol Cham: Springer International Publishing 2021:127-35.

https://doi .org/10.1007/978-3-030-50899-9_15

12. Carroll MP, Bulkhi AA, Lockey RF. Rhinitis and sinusitis. asthma, allerg immunol dis dur pregnancy. Cham: Springer International Publishing 2019:61-86. https://doi .org/10.1007/978-3-030-03395-8 5

13. Swain S, Pattnaik T, Mohanty J. Otological and rhinological manifestations in pregnancy: our experiences at a tertiary care teaching hospital of East India. Int J Heal Allied Sci 2020;9:159. https://doi .org/10.4103/ijhas.IJHAS_87_19

14. Papadopoulos NG, Guibas GV. Rhinitis subtypes, endotypes, and definitions. Immunol Allergy Clin North Am, Elsevier Inc 2016;36:215-33.

https://doi .org/10.1016/j.iac.2015.12.001

15. Crisci CD, Ardusso LRF. A Precision medicine approach to rhinitis evaluation and management. Curr Treat Options Allergy. Current Treatment Options in Allergy 2020;7:93-109. https://doi .org/10.1007/s40521-020-00243-1

16. Alhussien AH, Alhedaithy RA, Alsaleh SA. Safety of intranasal corticosteroid sprays during pregnancy: an updated review. Eur Arch Oto-Rhino-Laryngology. Springer Berlin Heidelberg 2018;275:325-33. https://doi .org/10.1007/s00405-017-4785-3

17. Namazy JA, Schatz M. The safety of intranasal steroids during pregnancy: a good start. J Allergy Clin Immunol. Elsevier Ltd 2016;138:105-6.

https://doi .org/10.1016/j.jaci.2016.04.026

18. Favilli A, Laurenti E, Stagni GM, Tassi L, Ricci G, Gerli S. Effects of sodium hyaluronate on symptoms and quality of life in women affected by pregnancy rhinitis: a pilot study. Gynecol Obstet Invest 2019;84:159-65. https://doi .org/10.1159/000493137

19. Uju IM, Semenitari AD, Surgery T. Ear nose and throat conditions seen in pregnant women attending Antenatal clinic in a tertiary hospital in Port. J Glob Biosci 2020;09:7019-33. 
20. Wu AW, Gettelfinger JD, Ting JY, Mort C, Higgins TS. Alternative therapies for sinusitis and rhinitis: a systematic review utilizing a modified Delphi method. Int Forum Allergy Rhinol 2020;10:496-504.

https://doi .org/10.1002/alr.22488

\section{PREGNANCY INDUCED RHINITIS}

\section{Juotkutè, D. Karaliūtè}

Keywords: pregnancy induced rhinitis, rhinitis, pregnancy, obstruction, nasal congestion.

Summary

Background. The purpose of the review is to elucidate main causes for pregnancy induced rhinitis and it's symptoms, as well as find out what methods of diagnosis and treatment are most commonly described in the literature.

Methods. It is a systematic literature review. Articles were selected from electronic database PubMed (Medline) with keywords „rhinitis during pregnancy“ and ,pregnancy induced rhinitis“.

Results. Rhinitis in pregnancy is a common diagnosis that might affect up to a half of all pregnant women. It is a condition that occurs only during pregnancy and manifests itself as a non - inflam- matory, non - allergic change in the nasal mucosa that causes one or more symptoms: nasal obstruction, rhinorrhea, nasal itching, sneezing, hyposmia. Rhinitis is caused by hormonal changes in the body during pregnancy. According to the literature, this condition disappears up to two weeks after childbirth, but if not diagnosed on time and without appropriate treatment methods, it can cause not only complications, but also worsen maternal and fetal outcomes. Therefore, it is very important cooperation of otorhinolaryngologists and obstetricians-gynecologists in the disease management.

Conclusions. Pregnancy rhinitis often causes symptoms that affect mother's and fetus' quality of life. Understanding the etiology of this pathology is particularly important in order to make safe diagnostic and treatment decisions.

Correspondence to: mantile.juotkute@gmail.com

Gauta 2021-03-04-08 